\title{
The role of collagen in co-cultures of human normal corneal and conjunctival cells
}

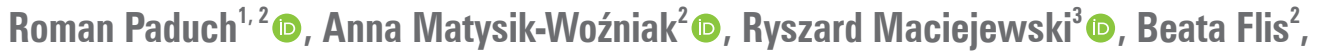 \\ Anselm G. Jünemann ${ }^{4} \mathbb{B}^{\text {, Robert Rejdak }}{ }^{2,5}$ (D) \\ 'Department of Virology and Immunology, Institute of Microbiology and Biotechnology, Maria Curie-Skłodowska University, Lublin, Poland \\ ${ }^{2}$ Department of General Ophthalmology, Medical University, Lublin, Poland \\ ${ }^{3}$ Department of Human Anatomy, Medical University, Lublin, Poland \\ ${ }^{4}$ Department of Ophthalmology, Rostock University Medical Centre, Rostock, Germany \\ ${ }^{5}$ Medical Research Centre, Polish Academy of Science, Warsaw, Poland
}

\begin{abstract}
BACKGROUND: Intermediate interactions between corneal and conjunctival epithelial cells play an important role in the process of correct vision. The goal of this paper was to establish whether the presence or absence of collagen type I changes paracrine interactions between corneal and conjunctival epithelial cells.

MATERIAL AND METHODS: Cultures of human corneal and conjunctival epithelial cells were used in the study. The ELISA quantitative analysis of interleukin $1 \beta$ (IL-1 $\beta$ ), interleukin 6 (IL-6), urokinase-type plasminogen activator (uPA), and uPA receptor (uPAR), assessment of the type of interactions between cells, as well as correlations between tested parameters were performed.

RESULTS: The presence of collagen type I changed the quantitative production of IL-1 $\beta$ and IL- 6 by the examined cells in the co-culture system. It did not affect the level of released UPA and uPAR. The presence or absence of collagen also changed the relationship between the cells, which were evaluated in relation to changes in the level of released cytokines.

CONCLUSIONS: Different levels of collagen type I constituting a component of extracellular matrix proteins significantly affect and regulate the indirect interactions between human corneal and conjunctival epithelial cells.
\end{abstract}

KEY WORDS: corneal epithelial cells; conjunctival epithelial cells; co-culture; cytokines; serine protease uPA; uPAR; collagen

Ophthalmol J 2019; Vol. 4, 77-85

\section{INTRODUCTION}

Indirect intercellular interactions play a very important role in maintaining homeostasis of tissues that they form as well as the surrounding microenvironment. These interactions are based on factors exhibiting biological interaction with cytokines, chemokines, and growth factors, among others. Apart from them, some enzymes also play an important role in tissue remodelling, including serine proteases, and urokinase-type plasminogen activator (uPA) and its receptor ( $\mathrm{UPAR}$ ). It has been shown that cells that form ocular tissues interact with each other in a direct and indirect way. Despite the lack of direct intercellular contact, corneal and conjunctival epithelial cells forming the eye surface closely influence each other through the interaction via paracrine mediators characteristic for the immune system [1]. 
Extracellular matrix (ECM) compounds are important factors that enable and regulate cellular adhesion, motility as well as metabolism. Among ECM components, collagen is known to be the most abundant protein influencing cellular phenotype as well as the expression of genes responsible for the production and release of e.g. cytokines and proteases [2]. Changes in collagen structure also strongly influence epithelial/mesenchymal transitions of cells like corneal resident stromal cells into myofibroblasts to avoid tissue destruction by inflammatory mediators and help in the healing process [3]. Therefore, it seems important to analyse how this element of the extracellular matrix regulates indirect interactions between selected cells of the eye. On the other hand, epithelial cells of the eye surface modulate ECM composition by releasing plasminogen system and pro-inflammatory compounds. IL- $1 \beta$ and IL- 6 are pro-inflammatory, pleiotropic cytokines that influence each other's local concentrations and simultaneously regulate homeostasis of tissues. Moreover, they facilitate the maintenance of physiologic functionality of epithelial cells of the ocular surface by induction of ECM remodelling enzymes including $\mathrm{uPA}$ and its receptor $[4,5]$. This serine protease catalyses the transformation of plasminogen to plasmin, which, in turn, modulates ECM components like collagen. It was already shown that upregulation of the expression of uPA and its receptor in ocular tissues may play a significant part in the processes of corneal wound healing [6]. These compounds are produced in various amounts by individual cells of the eye surface and in a paracrine fashion regulate the functionality of whole tissues. Therefore, the aim of our work was to assess the role of collagen type I in the modulation of indirect interactions between human corneal and conjunctival epithelial cells.

\section{MATERIAL AND METHODS CELL LINES}

A normal human corneal epithelial cell line, 10.014 pRSV-T (ATCC No. CRL-11515), and a human conjunctival epithelial cell line, HC0597 (LGC Standards, UK), were used. The cells were cultured as monolayers in $25-\mathrm{cm}^{2}$ culture flasks $\left(\mathrm{Nunc}^{\mathrm{TM}}\right.$, Roskilde, Denmark) coated with PureColTM ultrapure collagen type I (INAMED Biomaterials, Fremont, CA, USA) at $3.1 \mathrm{mg} / \mathrm{mL}$ concentration (about $12 \mu \mathrm{g} / \mathrm{cm}^{2}$ ). The cell lines were maintained in defined keratinocyte serum-free medium
(K-SFM) (Gibco ${ }^{\mathrm{TM}}$, Paisley, UK) supplemented with $75 \mu \mathrm{g} / \mathrm{mL}$ endothelial cell growth factor (ECGF) (Sigma, St. Louis, MO, USA), $0.05 \mathrm{mg} / \mathrm{mL}$ bovine pituitary extract (BPE) (Gibco), $500 \mathrm{ng} / \mathrm{mL}$ hydrocortisone (Sigma), $0.0005 \mathrm{mg} / \mathrm{mL}$ bovine insulin (Gibco), and antibiotics (100 U/mL penicillin, $100 \mu \mathrm{g} / \mathrm{mL}$ streptomycin) (Sigma, St Louis, MO, USA) at $37^{\circ} \mathrm{C}$ in a humidified atmosphere with $5 \%$ $\mathrm{CO}_{2}$.

\section{EXPERIMENTAL DESIGN}

Cells were cultured in 24-well plates ( $\mathrm{Nunc}^{\mathrm{TM}}$ ) and in polycarbonate membrane inserts ( $\mathrm{Nunc}^{\mathrm{TM}}$ ) with a pore size of $0.4 \mu \mathrm{m}$. Only the inserts were covered with collagen or in a parallel variant were left without coating with this extracellular protein. Cells were seeded on the well bottom and inside the inserts at a density of $1 \times 10^{5}$ cells $/ \mathrm{mL}$. After $24 \mathrm{~h}$ of inoculation, the medium was renewed, and the culture was conducted for a further $24 \mathrm{~h}$. After that time, culture supernatants only from the inserts were collected and analysed for the levels of cytokines (IL-1 $\beta$, IL-6), serine protease (uPA), and its receptor (uPAR).

The following experimental setups were used:

- corneal/conjunctival epithelial cells cultured in multi-dish polycarbonate membrane inserts, while conjunctival/corneal epithelial cells cultured at the bottom of a 24-well plate (Co-culture systems);

- corneal or conjunctival epithelial cells cultured only at the multi-dish polycarbonate membrane inserts (Monocultures);

- corneal or conjunctival epithelial cells cultured only at the bottom of a 24-well plate (Monocultures)

In the further part of the study the following terms were used (Fig. 1):

- co-culture model 1: pRSV-T corneal epithelial cells were cultured on the well bottom and HC0597 conjunctival epithelial cells were cultured on the insert;

- co-culture model 2: HC0597 conjunctival epithelial cells were cultured on the well bottom, and pRSV-T corneal epithelial cells were cultured on the insert.

\section{ELISA ASSAY}

The levels of human IL-1 $\beta$, IL-6 (BD OptEIA ${ }^{\mathrm{TM}}$, San Jose, CA, USA), uPA, and uPAR (R\&D Systems, Inc., Minneapolis, MN, USA) were measured immunoenzymatically (ELISA) using commercially 


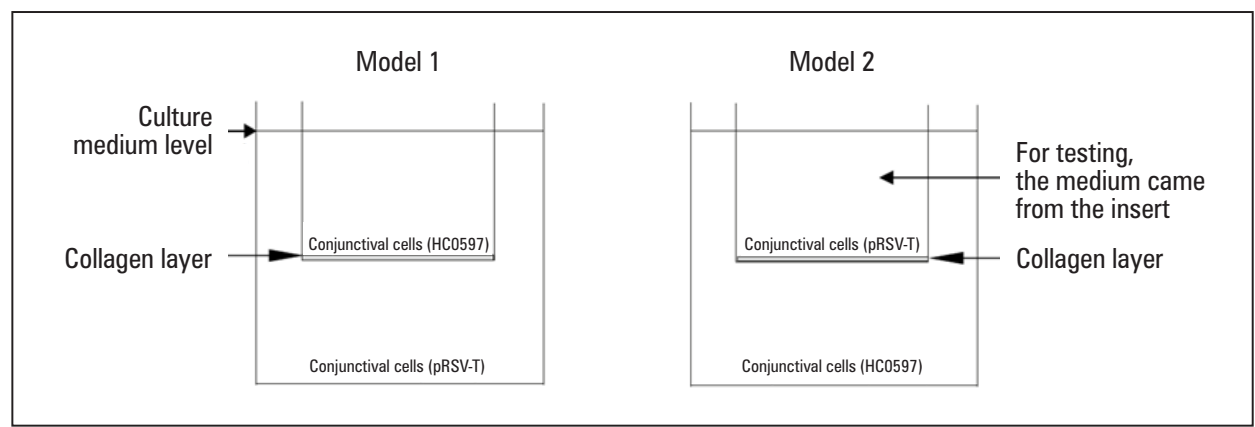

FIGURE 1. The scheme of experimental co-culture models used in the study. The membrane of the insert, on which corneal or conjunctival epithelial cells were cultured, depending on the model, was coated with collagen type I. At the bottom of the well, the conjunctival or corneal epithelial cells were then cultured, respectively. The liquid from the insert was used for the tests

available kits according to the manufacturers' instructions. Briefly, $100 \mu \mathrm{l}$ of samples were added to appropriate plate wells. After incubation $(2 \mathrm{~h})$ and a series of washings, enzyme-conjugated secondary antibodies $(100 \mu \mathrm{l})$ were added to the wells and incubated for $1 \mathrm{~h}$. After washing, detection was performed by adding $100 \mu \mathrm{l}$ of the enzyme substrate to the wells. After $30 \mathrm{~min}$ of incubation, the colour reaction was stopped by adding $2 \mathrm{M} \mathrm{H}_{2} \mathrm{SO}_{4}$ to each well. The optical density of the end product was determined using a microplate reader (Molecular Devices Corp., Emax) at $450 \mathrm{~nm}$. The concentrations of the cytokines in the analysed samples of supernatant were calculated on the basis of a standard curve. The detection limit was $2 \mathrm{pg} / \mathrm{mL}$ (IL-1 $\beta$ ), $2.2 \mathrm{pg} / \mathrm{mL}$ (IL-6), $4.17 \mathrm{pg} / \mathrm{mL}$ (uPA), and $33 \mathrm{pg} / \mathrm{mL}$ (uPAR).

\section{ANALYSIS OF INTERACTIONS BETWEEN CELL CULTURES}

The effect of paracrine interactions between the two cell cultures (corneal and conjunctival epithelia) was analysed using the interaction index according to Kerry et al. [7]. This index, represented by the symbol I, is defined by the following formula:

$$
I=a / X^{*} b / Y
$$

where: $\mathrm{I}$ - index value; $\mathrm{X}$ and $\mathrm{Y}$ - the activity of each culture considered separately; $\mathrm{a}$ and $\mathrm{b}$ - the activities of culture combinations.

If the index values range between 0.7 and 1.3, the interactions are additive, an index value lower than 0.7 indicates synergistic interactions, while a value higher than 1.3 indicates antagonistic interdependencies between the analysed parameters. The analysis covered the levels of tested molecules pro- duced by the corneal and conjunctival epithelia cultured separately during their paracrine interactions as well as culture surface condition (covered or not with collagen).

\section{STATISTICAL ANALYSIS}

The results are presented as mean \pm SD of three independent experiments $(n=3)$. The data were analysed using one-way analysis of variance ANOVA followed by Bonferroni's multiple comparison post-hoc test. Differences of $\mathrm{p} \leq 0.05$ were considered significant. Correlations among the levels of tested compounds (IL- $1 \beta$, IL- 6 , uPA and uPAR) in co-cultures were calculated using Spearman's rank correlation analysis. Only results with a significance of $\mathrm{p} \leq 0.05$ were reported.

\section{RESULTS}

Figure 1 shows a schematic experimental setup of cellular co-culture.

Significant differences in the production of cytokines (IL- $1 \beta$ and IL-6) have been demonstrated in both co-cultures and monocultures of corneal and conjunctival epithelial cells depending on the presence of collagen as an adhesive agent. When the inserts were coated with collagen and seeded with corneal pRSV-T cells, stimulation of cytokine production was observed in relation to the tests in which the insert membrane was not covered by this extracellular matrix element. A reverse dependency was obtained when conjunctival HC0597 cells were grown in the insert. These dependencies were observed both in co- and monocultures. The lowest amounts of cytokines were produced by the monoculture of pRSV-T cells (Fig. 2 and 3). In the case of UPA and UPAR protein analysis, there were no 


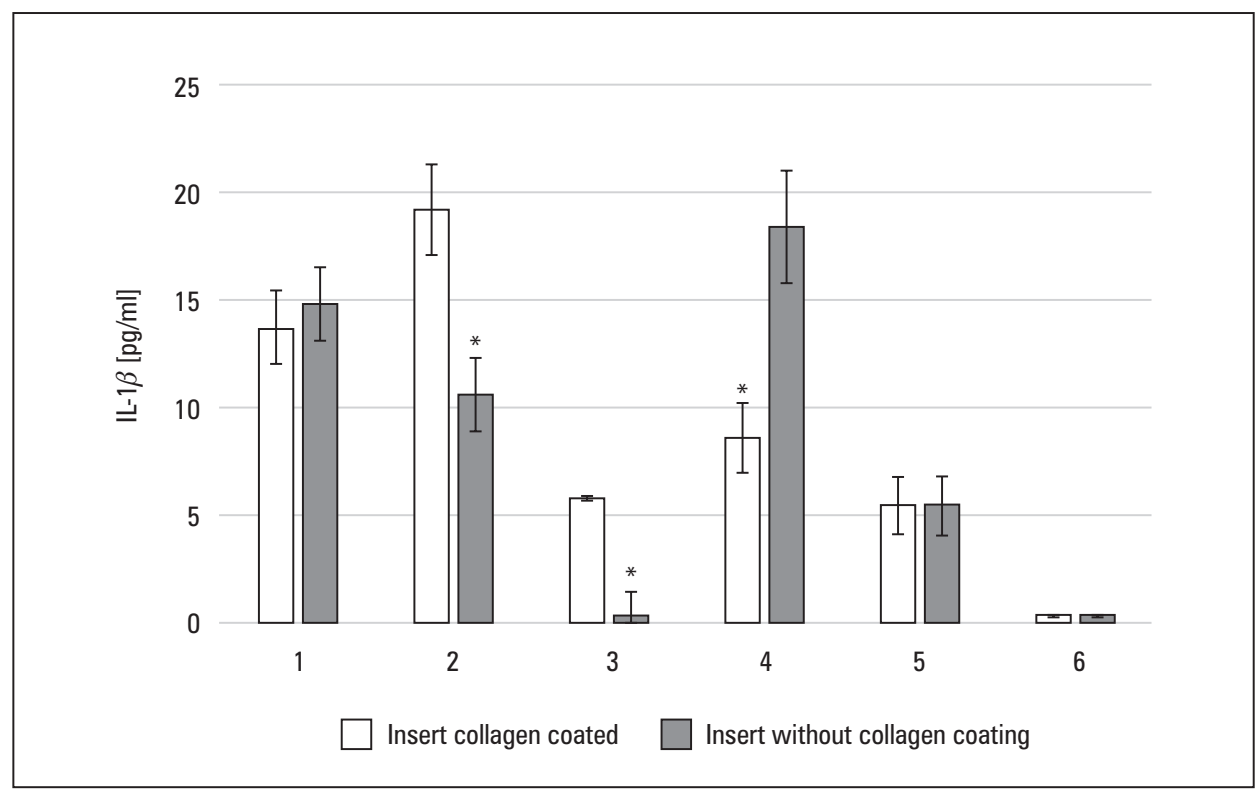

FIGURE 2. Interleukin $1 \beta$ (IL-1 $\beta$ ) release in the experimental models of co-culture of human corneal and conjunctival epithelial cells. ELISA test. Columns and bars show the mean \pm standard deviation $(n=3) .{ }^{*} p \leq 0.05$ comparison of appropriate samples cultured in systems with and without collagen coating of the insert. 1. Co-culture: pRSV-T corneal cells cultured on the well bottom and HC0597 conjunctival cells cultured on the insert 2. Co-culture: HC0597 conjunctival cells cultured on the well bottom and pRSV-T corneal cells cultured on the insert 3. Monoculture: pRSV-T corneal cells cultured on the insert 4. Monoculture: HC0597 conjunctival cells cultured on the insert 5. Monoculture: HC0597 conjunctival cells cultured on the well bottom 6. Monoculture: pRSV-T corneal cells cultured on the well bottom

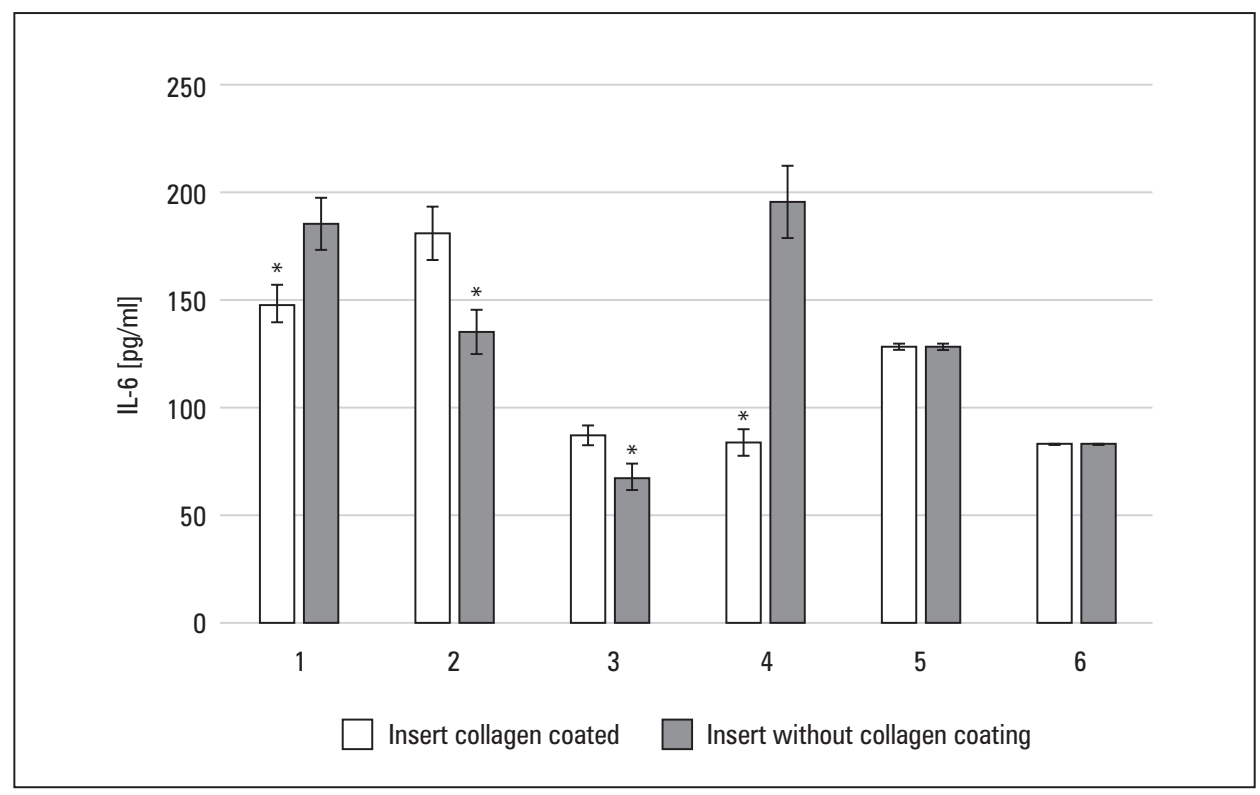

FIGURE 3. Interleukin 6 (IL-6) release in the experimental models of co-culture of human corneal and conjunctival epithelial cells.

ELISA test. Columns and bars show the mean \pm standard deviation $(n=3) .{ }^{*} p \leq 0.05$ comparison of appropriate samples cultured in systems with and without collagen coating of the insert. 1. Co-culture: pRSV-T corneal cells cultured on the well bottom and HC0597 conjunctival cells cultured on the insert 2. Co-culture: HC0597 conjunctival cells cultured on the well bottom and pRSV-T corneal cells cultured on the insert 3. Monoculture: pRSV-T corneal cells cultured on the insert 4. Monoculture: HC0597 conjunctival cells cultured on the insert 5. Monoculture: HC0597 conjunctival cells cultured on the well bottom 6. Monoculture: pRSV-T corneal cells cultured on the well bottom

significant differences between the production of these factors and covering the insert with collagen.
The only exception was the production of uPA by the monoculture of HC0597 cells (Fig. 4 and 5). 


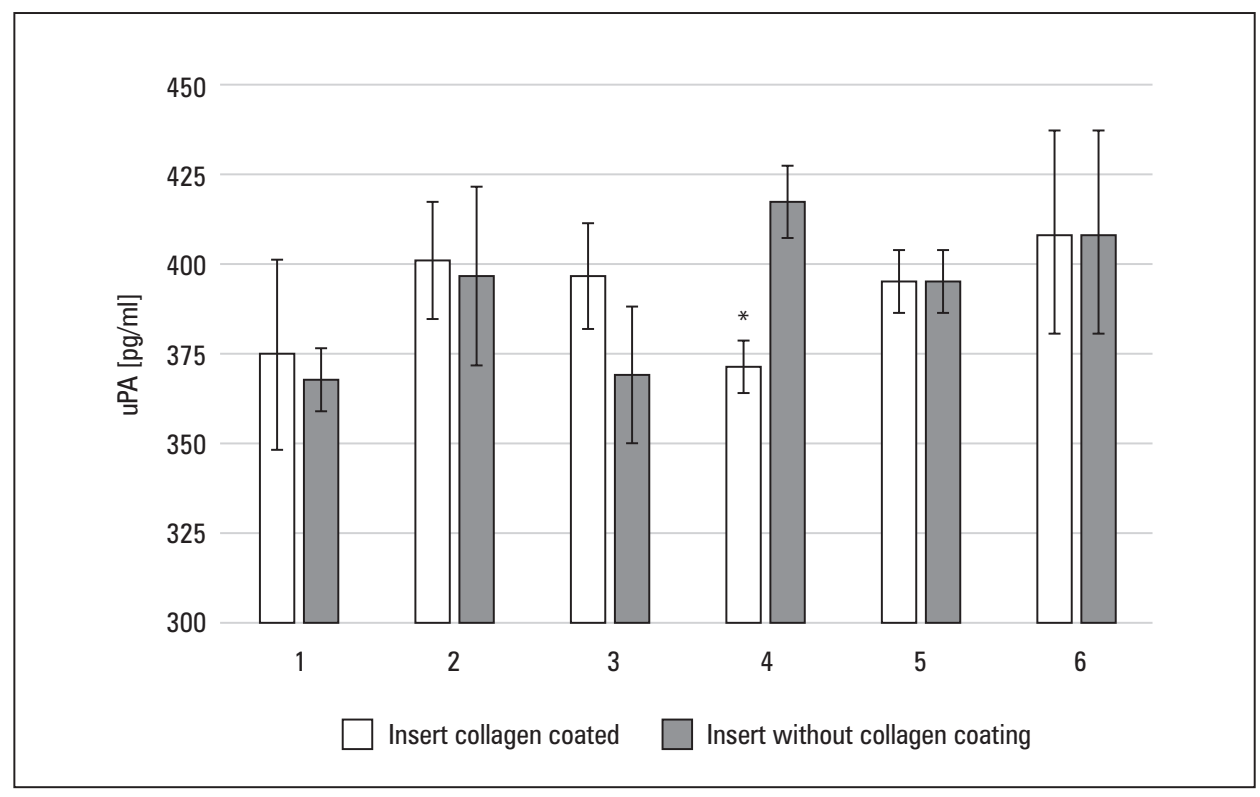

FIGURE 4. Urokinase-type plasminogen activator (UPA) release in the experimental models of co-culture of human corneal and conjunctival epithelial cells. ELISA test. Columns and bars show the mean \pm standard deviation $(n=3)$. ${ }^{*} p \leq 0.05$ comparison of appropriate samples cultured in systems with and without collagen coating of the insert. 1. Co-culture: pRSV-T corneal cells cultured on the well bottom and HCO597 conjunctival cells cultured on the insert 2. Co-culture: HC0597 conjunctival cells cultured on the well bottom and pRSV-T corneal cells cultured on the insert 3. Monoculture: pRSV-T corneal cells cultured on the insert 4. Monoculture: HC0597 conjunctival cells cultured on the insert 5. Monoculture: HC0597 conjunctival cells cultured on the well bottom 6. Monoculture: pRSV-T corneal cells cultured on the well bottom

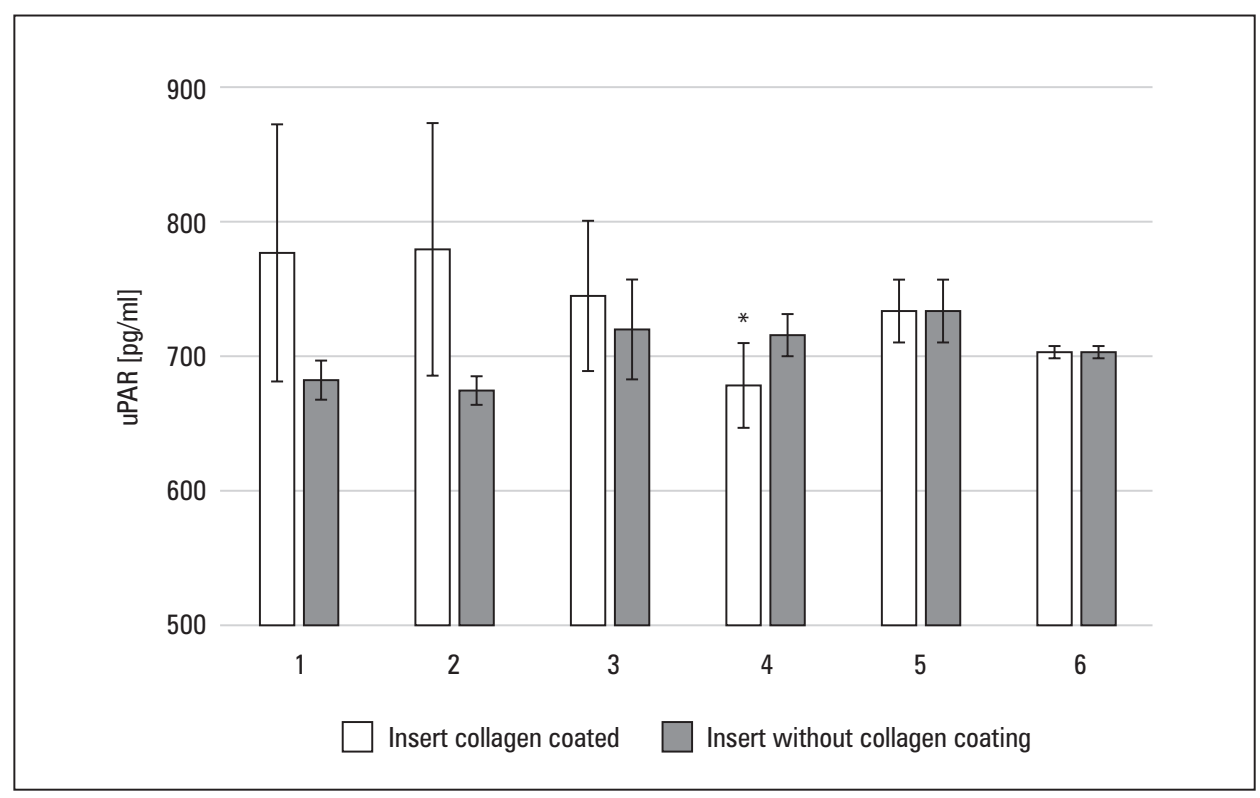

FIGURE 5. Urokinase-type plasminogen activator receptor (UPAR) release in the experimental models of co-culture of human corneal and conjunctival epithelial cells. ELISA test. Columns and bars show the mean \pm standard deviation $(n=3)$. 1. Co-culture: pRSV-T corneal cells cultured on the well bottom and HC0597 conjunctival cells cultured on the insert 2. Co-culture: HC0597 conjunctival cells cultured on the well bottom and pRSV-T corneal cells cultured on the insert 3. Monoculture: pRSV-T corneal cells cultured on the insert 4. Monoculture: HC0597 conjunctival cells cultured on the insert 5. Monoculture: HC0597 conjunctival cells cultured on the well bottom 6. Monoculture: pRSV-T corneal cells cultured on the well bottom 


\begin{tabular}{|c|c|c|c|}
\hline \multirow{2}{*}{ Compound } & \multirow{2}{*}{$\begin{array}{l}\text { Collagen coating } \\
\text { of the insert membrane }\end{array}$} & \multicolumn{2}{|c|}{ Ratio of interactions } \\
\hline & & Experimental system 1 & Experimental system 2 \\
\hline \multirow{2}{*}{ IL-1 $\beta$} & Coated & $\begin{array}{c}0.66 \\
\text { Synergism }\end{array}$ & $\begin{array}{c}0.59 \\
\text { Synergism }\end{array}$ \\
\hline & Non-coated & $\begin{array}{c}1.26 \\
\text { Additivity }\end{array}$ & $\begin{array}{c}0.58 \\
\text { Synergism }\end{array}$ \\
\hline \multirow{2}{*}{ IL-6 } & Coated & $\begin{array}{c}1.14 \\
\text { Additivity }\end{array}$ & $\begin{array}{l}1.19 \\
\text { Additivity }\end{array}$ \\
\hline & Non-coated & $\begin{array}{c}1.51 \\
\text { Antagonism }\end{array}$ & $\begin{array}{c}1.45 \\
\text { antagonism }\end{array}$ \\
\hline \multirow{2}{*}{ UPA } & Coated & $\begin{array}{c}2.08 \\
\text { Antagonism }\end{array}$ & $\begin{array}{c}1.97 \\
\text { antagonism }\end{array}$ \\
\hline & Non-coated & $\begin{array}{c}2.2 \\
\text { Antagonism }\end{array}$ & $\begin{array}{c}1.93 \\
\text { Antagonism }\end{array}$ \\
\hline \multirow{2}{*}{ UPAR } & Coated & $\begin{array}{c}1.78 \\
\text { Antagonism }\end{array}$ & $\begin{array}{c}1.9 \\
\text { Antagonism }\end{array}$ \\
\hline & Non-coated & $\begin{array}{c}2.08 \\
\text { Antagonism }\end{array}$ & $\begin{array}{c}2.15 \\
\text { Antagonism }\end{array}$ \\
\hline
\end{tabular}

IL-1 1 - interleukin 1 $\beta$, IL-6 - interleukin 6; uPA — urokinase-type plasminogen activator; uPAR — uPA receptor; Quotient lower than 0.7 indicates synergism of reciprocal interaction between corneal and conjunctival cells; Quotient higher than 1.3 indicates antagonism of interactions; Quotient in the range $0.7-1.3$ indicates additive relations between cell cultures. Experimental system 1 - conjunctival epithelial cells in the insert; corneal epithelial cells on the plate bottom; experimental system 2 - corneal epithelial cells in the insert; conjunctival epithelial cells on the plate bottom

The co-culture of corneal and conjunctival epithelial cells caused a synergistic or at least additive effect with reference to the level of IL- $1 \beta$ as compared to the sum of the concentrations of this cytokine in particular monocultures. Similarly, the synergistic effect of IL-6 production was observed in the case of the co-culture of these cells when the insert membrane was coated with collagen. On the other hand, the lack of collagen caused antagonism in the production of IL-6 in this model. The mutual indirect relationship between corneal and conjunctival epithelial cells significantly limited uPA production (antagonistic effect) and release of its receptor (uPAR) in comparison to the sum of concentrations of these factors in the respective monocultures (Tab. I).

The study of the functional correlation between the investigated factors in the co-culture systems in the presence or absence of insert membrane covering with collagen is presented in Table II. Depending on the set of the analysed parameters and the research system, both positive and negative correlations were observed. Particularly noteworthy is the negative correlation between the level of IL- $1 \beta$ and IL- 6 in the co-culture of systems 1 and 3 (HC0597 cells in the insert, pRSV-T cells on the well bottom) regardless of the collagen coating of the insert membrane. In addition, the positive correlation between IL- 6 and the serine protease $\mathrm{uPA}$ and its receptor (uPAR) obtained in System 1 (collagen-coated insert membrane, HC0597 cells in the insert, pRSV-T cells on the well bottom) is also noteworthy.

\section{DISCUSSION}

The tissues of the external part of the eye are exposed not only to damaging mechanical stimuli but also to many biological factors that stimulate the immune response. Therefore, the mutual relations between the tissues of this part of the eye fulfil an extremely important role in the process of proper vision. It is already known that epithelial cells of the cornea and conjunctiva interact with each other in a paracrine manner, and the function of these physically apposed tissues is strictly regulated by the factors of the immune system [1, 8]. The source of biologically active factors are not only the immune competent cells present in the mucosal layer but also the corneal and conjunctival epithelial cells themselves [8]. The regulatory role in the indirect interactions between these cells is therefore played by cytokines, chemokines, and growth factors, as well as extracellular matrix 
Table II. The Spearman rank coefficients of significant correlations between tested parameters in the analysed co-culture experimental conditions

\begin{tabular}{|c|c|c|c|c|}
\hline \multirow{2}{*}{ Variable } & \multicolumn{4}{|c|}{ Spearman's rank correlations. Results are statistically significant at $p<0.05$} \\
\hline & IL- $1 \beta$ & IL-6 & UPA & UPAR \\
\hline IL-1 $\beta$ & - & -0.828571 & NC & NC \\
\hline IL-6 & -0.82857 & - & 0.828571 & 0.82857 \\
\hline uPA & NC & 0.828571 & - & NC \\
\hline UPAR & NC & 0.828571 & NC & - \\
\hline \multicolumn{5}{|c|}{ System 2: Insert membrane collagen coated, pRSV-T cells in the insert, HC0597 cells on the well bottom } \\
\hline \multicolumn{5}{|c|}{ There were no significant correlations between tested parameters } \\
\hline \multicolumn{5}{|c|}{ System 3: Insert membrane without collagen coating, HC0597 cells in the insert, pRSV-T cells on the well bottom } \\
\hline \multirow{2}{*}{ Variable } & \multicolumn{4}{|c|}{ Spearman's rank correlations. Results are statistically significant at $p<0.05$} \\
\hline & IL- $1 \beta$ & IL-6 & UPA & UPAR \\
\hline $\mathrm{IL}-1 \beta$ & - & -0.94286 & NC & 0.94286 \\
\hline IL-6 & -0.942857 & - & NC & NC \\
\hline UPA & NC & NC & - & NC \\
\hline UPAR & 0.942857 & NC & NC & - \\
\hline \multicolumn{5}{|c|}{ System 4: Insert membrane without collagen coating, pRSV-T cells in the insert, HC 0597 cells on the well bottom } \\
\hline \multirow{2}{*}{ Variable } & \multicolumn{4}{|c|}{ Spearman's rank correlations. Results are statistically significant at $p<0.05$} \\
\hline & IL- $1 \beta$ & IL-6 & UPA & UPAR \\
\hline $\mathrm{IL}-1 \beta$ & - & NC & -0.942857 & NC \\
\hline IL-6 & $\mathrm{NC}$ & - & NC & 0.942857 \\
\hline UPA & -0.942857 & $\mathrm{NC}$ & - & $\mathrm{NC}$ \\
\hline UPAR & NC & 0.942857 & NC & - \\
\hline
\end{tabular}

IL-1 $\beta$ - interleukin 1 $\beta$, IL-6 — interleukin 6; uPA — urokinase-type plasminogen activator; uPAR — UPA receptor; NC — no correlation between tested parameters; R Spearman and $p$ value $(p<0.05)$

(ECM) proteins. The ECM provides mechanical strength within the tissue but also mediates interaction and communication between cells [9]. Among ECM proteins, collagen, including collagen type I, has been found to be important in maintaining the proper structure and functionality of the ocular surface tissues $[10,11]$.

The expression of inflammatory cytokines is closely regulated by ECM proteins, including collagen. On the other hand, cytokines like IL- 4 or IL-13 as well as IL- $1 \beta$ or IL- 6 may contribute to increased or changed ECM protein deposition [12, 13]. In addition, the cytokine network influences the release of proteases, including MMPs and serine proteases, which modulate the ECM structure. Therefore, these are mutual, quite complex interactions that need to be studied.

In our study we found significant changes in IL-1 $\beta$ and IL- 6 levels depending on the co-culture model applied and the presence of collagen. IL- $1 \beta$ is constitutively present in the tear film and was found to be present in corneal and conjunctival epithelial cells [14]. IL-1 $\beta$ is an important modulator of corneal epithelium and stroma activity. This cytokine together with IL-6 stimulate the activity of ocular surface epithelial and immune cells in response to injury, activate corneal cell migration, and regulate the proliferation and differentiation of epithelial cells $[5,15,16]$. Both cytokines are recognised as factors that strongly stimulate inflammation [17, 18]. In addition, the regulation of their formation by affecting molecular pathways like NF- $\kappa \mathrm{B}$ may limit the adverse effects associated with inflammation [17]. Based on our results, we believe that modulation of the formation of cytokines through extracellular matrix proteins may also be an alternative factor helping in the reduction of eye inflammation. Moreover, taking our results into account, indirect interactions between corneal and conjunctival epithelial cells mediated by pro-inflammatory cytokines do not necessarily have to participate only in the development of inflammation that is unfavourable to the surface of the eye but may also serve as physiological relays that allow contact between 
these cells and thus the proper functioning of the tissue. What is more, we believe that extracellular matrix proteins may modulate pro-inflammatory cytokine production and may serve as an alternative to reduce inflammation of the eye. On the other hand, these cytokines may locally induce matrix metalloproteinase (MMPs) or serine protease activity, which may directly or indirectly modulate ECM protein production or their destruction [4, 19, 20]. Inflammation has also been shown to alter the expression of MMPs or serine proteases in the conjunctival tissue, which may initiate collagenous fibre melting [21]. In our study, we found that the presence of collagen type I does not significantly change urokinase-type plasminogen activator ( $\mathrm{uPA}$ ) and its receptor ( $\mathrm{UPAR}$ ) production in the co-culture models. Nevertheless, the level of these factors was relatively high in our experimental models. This observation may result from uPA substrate specificity mainly for fibrin, fibronectin, or laminin. Collagen is not an essential substrate for its activity. However, its production may stem from its functions directed at cell adhesion, migration, or microenvironment remodelling [22]. In our studies, we also demonstrated a high level of the soluble form of uPAR. It is indicated that, independently of uPA, this receptor can control the response and infiltration of leukocytes into the cornea and thus regulate local inflammation [23]. However, its interaction with uPA initiates a sequence of events that may lead to the development of blood vessels in the cornea and the induction of corneal vascularisation $[23,24]$. We analysed the degree of mutual relationships between the examined parameters stating that, depending on the experimental model, uPA and uPAR correlate with the examined cytokines. This may suggest that the activity of serine proteases is regulated by the cytokine presence in the co-culture microenvironment. In addition, the presence of collagen may, at least indirectly, via soluble immune mediators, regulate the processes of destruction or remodelling of the ocular surface stroma.

In conclusion, paracrine interactions between corneal and conjunctival epithelial cells depend on the composition of extracellular matrix proteins. They regulate not only the level of pro-inflammatory cytokines or, indirectly, serine proteases but also may change mutual cellular interactions from synergistic to antagonistic, as was demonstrated in the case of IL-6. Therefore, the process of correct vision depends not only on the functionalities of individual tissues and their reciprocal interactions but also on intermediate and direct relationships with stroma proteins.

\section{DECLARATION OF INTEREST}

The authors report no conflicts of interest. The authors alone are responsible for the content and writing of the paper.

\section{REFERENCES}

1. Fukuda K, Nishida T. Reciprocal interaction of the conjunctiva and cornea in ocular allergy. J Allergy Clin Immunol. 2010; 125(2): 493-496. e2, doi: 10.1016/j.jaci.2009.10.041, indexed in Pubmed: 20159262.

2. Song Y, Kim JS, Choi EK, et al. TGF- $\beta$-independent CTGF induction regulates cell adhesion mediated drug resistance by increasing collagen I in HCC. Oncotarget. 2017; 8(13): 21650-21662, doi: 10.18632/ oncotarget.15521, indexed in Pubmed: 28423507.

3. Sugioka K, Mishima H, Kodama A, et al. Regulatory Mechanism of Collagen Degradation by Keratocytes and Corneal Inflammation: The Role of Urokinase-Type Plasminogen Activator. Cornea. 2016; 35 Suppl 1: S59-S64, doi: 10.1097/IC0.0000000000000995, indexed in Pubmed: 27661072.

4. Lee JG, Heur M. Interleukin-1 $\beta$ enhances cell migration through AP-1 and NF- B pathway-dependent FGF2 expression in human corneal endothelial cells. Biol Cell. 2013; 105(4): 175-189, doi: 10.1111/ boc.201200077, indexed in Pubmed: 23331079.

5. Higuchi A, Kawakita T, Tsubota K. IL-6 induction in desiccated corneal epithelium in vitro and in vivo. Mol Vis. 2011; 17: 2400-2406, indexed in Pubmed: 21976951.

6. Wang Z, Sosne G, Kurpakus-Wheater M. Plasminogen activator inhibitor-1 (PAI-1) stimulates human corneal epithelial cell adhesion and migration in vitro. Exp Eye Res. 2005; 80(1): 1-8, doi: 10.1016/j. exer.2004.06.006, indexed in Pubmed: 15652520.

7. Kerry DW, Hamilton-Miller JM, Brumfitt W. Trimethoprim and rifampicin: in vitro activities separately and in combination. J Antimicrob Chemother. 1975; 1(4): 417-427, doi: 10.1093/jac/1.4.417, indexed in Pubmed: 1206027.

8. Irkeç $\mathrm{M}$, Bozkurt B. Epithelial cells in ocular allergy. Curr Allergy Asthma Rep. 2003; 3(4): 352-357, indexed in Pubmed: 12791215.

9. Dziasko MA, Daniels JT. Anatomical Features and Cell-Cell Interactions in the Human Limbal Epithelial Stem Cell Niche. Ocul Surf. 2016; 14(3): 322-330, doi: 10.1016/j.jtos.2016.04.002, indexed in Pubmed: 27151422.

10. Chang $\mathrm{JH}$, Huang $\mathrm{YH}$, Cunningham $\mathrm{CM}$, et al. Matrix metalloproteinase 14 modulates signal transduction and angiogenesis in the cornea. Surv Ophthalmol. 2016; 61(4): 478-497, doi: 10.1016/j. survophthal.2015.11.006, indexed in Pubmed: 26647161.

11. Park HY, Kim JH, Lee KM, et al. Effect of prostaglandin analogues on tear proteomics and expression of cytokines and matrix metalloproteinases in the conjunctiva and cornea. Exp Eye Res. 2012; 94(1): 13-21, doi: 10.1016/j.exer.2011.10.017, indexed in Pubmed: 22067128.

12. Fukuda K, Fujitsu Y, Kumagai N, et al. Inhibition of matrix metalloproteinase-3 synthesis in human conjunctival fibroblasts by interleukin-4 or interleukin-13. Invest Ophthalmol Vis Sci. 2006; 47(7): 2857-2864, doi: 10.1167/iovs.05-1261, indexed in Pubmed: 16799025

13. Bian F, Pelegrino FSA, Pflugfelder SC, et al. Desiccating Stress-Induced MMP Production and Activity Worsens Wound Healing in AlkaliBurned Corneas. Invest Ophthalmol Vis Sci. 2015; 56(8): 4908-4918, doi: 10.1167/iovs.15-16631, indexed in Pubmed: 26225631.

14. Heur M, Chaurasia SS, Wilson SE. Expression of interleukin-1 receptor antagonist in human cornea. Exp Eye Res. 2009; 88(5): 992-994, doi: 10.1016/i.exer.2008.11.019, indexed in Pubmed: 19087877.

15. Stapleton WM, Chaurasia SS, Medeiros FW, et al. Topical interleukin-1 receptor antagonist inhibits inflammatory cell infiltration into the cornea. Exp Eye Res. 2008; 86(5): 753-757, doi: 10.1016/j. exer.2008.02.001, indexed in Pubmed: 18346730.

16. Ebihara N, Matsuda A, Nakamura S, et al. Role of the IL-6 classicand trans-signaling pathways in corneal sterile inflammation and 
wound healing. Invest Ophthalmol Vis Sci. 2011; 52(12): 8549-8557, doi: 10.1167/iovs.11-7956, indexed in Pubmed: 21989726.

17. Xi X, McMillan DH, Lehmann GM, et al. Ocular fibroblast diversity: implications for inflammation and ocular wound healing. Invest Ophthalmol Vis Sci. 2011; 52(7): 4859-4865, doi: 10.1167/iovs.10-7066, indexed in Pubmed: 21571679.

18. Sakimoto T, Sugaya S, Ishimori A, et al. Anti-inflammatory effect of IL-6 receptor blockade in corneal alkali burn. Exp Eye Res. 2012; 97(1): 98104, doi: 10.1016/j.exer.2012.02.015, indexed in Pubmed: 22551515.

19. Iwatake A, Murakami A, Ebihara N. The expression of matrix metalloproteinases and their inhibitors in corneal fibroblasts by alarmins from necrotic corneal epithelial cells. Jpn J Ophthalmol. 2018; 62(1): 92-100, doi: 10.1007/s10384-017-0541-x, indexed in Pubmed: 29094325.

20. Sugaya S, Sakimoto T, Shoji J, et al. Regulation of soluble interleukin-6 (IL-6) receptor release from corneal epithelial cells and its role in the ocular surface. Jpn J Ophthalmol. 2011; 55(3): 277-282, doi: 10.1007/ s10384-011-0002-x, indexed in Pubmed: 21523377.
21. Xiang $M H$, Zhang $X R$, Zhang $Z Y$, et al. Expressions of matrix metalloproteinases 1 and 3 and their tissue inhibitors in the conjunctival tissue and fibroblasts cultured from conjunctivochalasis. Int $\mathrm{J}$ Ophthalmol. 2017; 10(4): 555-559, doi: 10.18240/ijo.2017.04.09, indexed in Pubmed: 28503427.

22. Watanabe M, Yano W, Kondo S, et al. Up-regulation of urokinase-type plasminogen activator in corneal epithelial cells induced by wounding. Invest Ophthalmol Vis Sci. 2003; 44(8): 3332-3338, doi: 10.1167/ iovs.02-1280, indexed in Pubmed: 12882778.

23. Sugioka K, Kodama A, Yoshida K, et al. The roles of urokinase-type plasminogen activator in leukocyte infiltration and inflammatory responses in mice corneas treated with lipopolysaccharide. Invest Ophthalmol Vis Sci. 2014; 55(8): 5338-5350, doi: 10.1167/iovs.1414867, indexed in Pubmed: 25061113.

24. Swamynathan S, Swamynathan SK. SLURP-1 modulates corneal homeostasis by serving as a soluble scavenger of urokinase-type plasminogen activator. Invest Ophthalmol Vis Sci. 2014; 55(10): 6251-6261, doi: 10.1167/iovs.14-15107, indexed in Pubmed: 25168896. 